\title{
Un ensayo sociológico sobre la prostitución
}

\author{
Rosa Coвo Bedia \\ Universidad de La Coruña \\ rosa.cobo@udc.es
}

Recibido: 01-03-2015

Aceptado: 21-04-2016

\section{Resumen}

El objetivo de este trabajo es analizar algunas realidades sociales que envuelven el debate sobre la prostitución. La idea fundamental que argumentaré es que la prostitución, hasta la aparición del capitalismo neoliberal, ha tenido un carácter exclusivamente patriarcal. Sin embargo, cuando las políticas económicas neoliberales comienzan a aplicarse globalmente, la prostitución deja de ser sólo una práctica patriarcal y se convierte en un sector económico fundamental para la economía internacional y especialmente para la economía criminal. Por eso, la prostitución debe analizarse en el marco de la economía política. Asimismo, se explicará que la prostitución es un fenómeno social que se desarrolla en el marco de tres sistemas de dominio: el patriarcal, el capitalista neoliberal y el racial/cultural.

Palabras clave: Sociología; prostitución; feminismo; capitalismoneoliberal; contrato sexual; hipersexualización.

\section{A Sociological Essay about Prostitution}

\begin{abstract}
The aim of this work is to analyze some discourses and practices which surrounds the debate about the prostitution. The fundamental idea which I argue is that prostitution, until the appearance of the neoliberal capitalism, has had an exclusively patriarchal nature. However, when neoliberal economic policies begin to be applied globally, prostitution stops to be only a patriarchal practice and becomes into a fundamental economic sector for the international economy and especially for the criminal economy. Thereby prostitution should be analyzed in the frame of the political economy. Likewise, I explain that prostitution is a social phenomenon that develops within the frame of three systems of control: the patriarchal, the neoliberal capitalist and the racial/cultural.
\end{abstract}

Key words: Sociology; prostitution; feminism; neoliberal capitalism; sexual contract; hypersexualization.

\section{Referencia normalizada}

Cobo Bedia, R. (2016): “Un ensayo sociológico sobre la prostitución”, Política y Sociedad, 53 (3), pp. 897-914.

Sumario: Introducción. 1. Naturalización de la prostitución. 2. De la cultura del sexo a la cultura de la prostitución. 3. Economía política de la prostitución. 4. El papel de los varones en la prostitución. 5. Consentimiento y coacción en la prostitución. 6. Reflexiones finales. 7. Bibliografía. 


\section{Introducción}

La prostitución es una antigua práctica social que ha experimentado cambios profundos en las últimas décadas. La globalización neoliberal ha cambiado el rostro de la prostitución, pues de ser una realidad social reducida se ha convertido en una gran industria global que moviliza miles de millones de euros anuales. La idea fundamental que quiero argumentar es que la prostitución, hasta la aparición de esta nueva fase del capitalismo, ha tenido un carácter exclusivamente patriarcal. Sin embargo, cuando las políticas económicas neoliberales se aplican globalmente, la prostitución deja de ser solo una práctica patriarcal y se convierte también en un sector económico crucial para la economía internacional y especialmente para la economía ilícita.

La prostitución del siglo XXI es el resultado de la convergencia entre los intereses patriarcales y los neoliberales. Richard Poulin, uno de los mayores expertos mundiales sobre prostitución, explica que esta industria revela las tendencias actuales en la agenda de la globalización neoliberal, pues nos "permite entender mejor la mercantilización de la vida y de los seres humanos, la discriminación étnica, la opresión sexual y la sumisión de mujeres y niñas al síndrome del placer masculino" (Poulin, 2009). Por eso, Poulin señala que la prostitución nos sitúa ante una elección de civilización. En efecto, esta práctica no sólo es el resultado de la dimensión más perversa del libre mercado sino también un test que revela la tensión y la lucha entre la esclavitud y la libertad, el capitalismo neoliberal y los proyectos políticos emancipadores, las estructuras patriarcales y las demandas feministas.

El creciente aumento de la industria del sexo se encuentra en el cruce de dos formas de dominio: la patriarcal y la capitalista neoliberal. Sin embargo, una gran parte de la prostitución no puede entenderse fuera de otro dominio: el racial/cultural. El hecho de que la prostitución se explique en el marco de tres sistemas de poder hace que solo la teoría crítica pueda desvelar los mecanismos opresivos que subyacen a esta práctica social. En efecto, el análisis feminista desvela que es una práctica de subordinación patriarcal, mientras que la economía crítica muestra la explotación económica a la que están sometidas las mujeres prostituidas. La perspectiva crítica étnico-racial descubre el racismo en el comportamiento de los varones demandantes, pero también en la composición racial y cultural de las mujeres en la industria de la prostitución.

En primer lugar, el pensamiento feminista "analiza la prostitución como un soporte del control patriarcal y de la sujeción sexual de las mujeres, con un efecto negativo no solamente sobre las mujeres y las niñas que están en la prostitución, sino sobre el conjunto de mujeres como grupo, ya que la prostitución confirma y consolida las definiciones patriarcales de las mujeres, cuya función primera sería la de estar al servicio sexual de los hombres"(Hofman, 1997).

En segundo lugar, el nuevo capitalismo, con sus políticas económicas neoliberales y sus vínculos con la economía criminal, ha hecho de la prostitución uno de los sectores económicos que más beneficios proporcionan a escala global. La globalización neoliberal ha cambiado el rostro de la prostitución y ha puesto las bases de una nueva forma de esclavitud económica.

Por último, y en relación al dominio racial/cultural, los varones demandantes de los países occidentales buscan en la prostitución a mujeres racializadas en un claro 
mecanismo de colonialismo sexual, tal y como sostiene lúcidamente Jeffreys (2011: 17). Y este colonialismo sexual se observa tanto en el interior de las sociedades occidentales, donde la mayoría de las mujeres que ejercen la prostitución son africanas, latinoamericanas, orientales y de los países del este de Europa (Foundation Scelles, 2012), como en el turismo sexual de los demandantes, dirigido mayoritariamente a países postcoloniales y pobres.

Para dar cuenta de la complejidad de esta práctica social hay que diferenciar dos planos: el intelectual y el ético-normativo. Primero hay que examinar la naturaleza y las causas de este fenómeno social y, en consonancia con ese análisis intelectual, adoptar una posición ético-normativa respecto a su existencia. Si el punto de partida, tras estudiar la prostitución y las causas que la originan, es que esta práctica social es una forma deseable de vida y no puede ser definida como una forma de explotación sexual, entonces la conclusión lógica es legalizar y reglamentar la prostitución. Si, por el contrario, se considera la prostitución una forma inaceptable de vida, resultado del sistema de hegemonía masculina, vinculada a la dominación patriarcal y que vulnera los derechos humanos de las mujeres al convertir su cuerpo en una mercancía y en un objeto para el placer sexual de otros, entonces se concluye la imposibilidad de su legalización.

Sin embargo, esta aproximación a la prostitución requiere distinguir la prostitución, del colectivo concreto que son las mujeres prostituidas, pues esta distinción nos permitirá interpelar críticamente esa realidad social y al mismo tiempo diseñar políticas públicas para desactivar esta práctica social (Informe de la ponencia sobre prostitución en nuestro país. Cortes Generales, 2007). En otros términos, pondremos en tela de juicio la estructura de subordinación sexual y explotación económica y racial que subyace a la prostitución y, al mismo tiempo, afirmamos que el estado debe intervenir para eliminar esta institución. Dicho de otra forma, el fenómeno de la prostitución es un problema político que solo puede ser entendido en el marco de las estructuras patriarcales, neoliberales y raciales.

\section{Naturalización de la prostitución}

Las sociedades producen relatos sobre sí mismas y sobre los hechos sociales que componen su entramado social. Esos relatos tienen como función que los individuos acepten el orden social. Y es por eso que no son estáticos, ni fijos, ni inmutables. Están en permanente proceso de construcción y reconstrucción. Sin estas narraciones, los hechos sociales no pueden tener un lugar estable en el imaginario colectivo.

Todo fenómeno social debe estar sometido a procesos permanentes de legitimación con el objeto de que pueda reproducirse a lo largo de extensos periodos históricos. La primera legitimación de cualquier fenómeno social se encuentra en su propia facticidad, que, por otra parte, siempre tiene un carácter autolegitimador. El hecho de que una realidad social haya existido durante largos periodos históricos es utilizada para sugerir que forma parte de un 'orden natural' de las cosas imposible de alterar. Si, además de existir, también ha sobrevivido a intentos de acabar con esa realidad, como, por ejemplo, la legislación prohibicionista o la penalización moral de la prostitución, entonces parece 
que tiene una fuerza que va más allá de lo puramente social. Sin embargo, la facticidad no puede ser la única fuente de legitimación, pues por sí misma sería insuficiente. Se necesitan otras legitimaciones adicionales, cuya intensidad y grado de elaboración debe ser proporcional al cuestionamiento de la realidad social que se quiere legitimar (Berger, 1981: capítulo 2).

El debate que existe en torno a la legalización o abolición de la prostitución explica la poderosa interpelación social a la que está sometida esta práctica y, al mismo tiempo, pone de manifiesto los poderosos intereses que se juegan en torno a esta gran industria. Por eso se han puesto sobre la mesa otras legitimaciones secundarias, desde la reactualización de ideas pre-teóricas hasta argumentaciones desarrolladas en el marco del pensamiento académico. La producción de prejuicios y estereotipos para que la prostitución sea aceptada socialmente se suceden: desde señalar que es el oficio más viejo del mundo hasta advertir sobre la urgencia sexual natural de los varones; desde vincular esta práctica social con la libertad sexual hasta considerar que la prostitución es una poderosa barrera que protege a las otras mujeres de las violaciones y agresiones sexuales masculinas; desde la argumentación de que la postura sobre la abolición es moralista hasta la idea de que quienes sostienen que hay que erradicar la prostitución están en contra de las mujeres prostituidas. El conjunto de prejuicios y estereotipos es muy amplio y se reelabora permanentemente para producir nuevas legitimaciones. Por otra parte, desde instancias académicas se realizan investigaciones que intentan fundamentar la legitimidad de la prostitución en el consentimiento de las mujeres prostituidas, sin mostrar la prostitución como el resultado de la jerarquía patriarcal y sin señalar suficientemente el vínculo entre prostitución y capitalismo neoliberal (Juliano, 2002; Osborne, 2004; Maqueda, 2009).

Pues bien, la prostitución es un fenómeno social que tiene su propio relato. Uno de los argumentos estables de esta narración, fuertemente arraigada en el imaginario colectivo, que, por otra parte, siempre es patriarcal, es que la prostitución surge espontáneamente en cualquier comunidad humana. La idea que debe aceptar la sociedad y, por ello, debe anclarse en las estructuras simbólicas, es que la prostitución es un hecho natural. Uno de los subtextos del imaginario de la prostitución sugiere que está profundamente anclada en algún oscuro lugar de la naturaleza humana. Y éste es, desde luego, uno de los problemas que obstaculizan una posición crítica frente a la prostitución, pues con esos argumentos se coloca a esta práctica social en el orden de lo pre-político. En efecto, si el fundamento de esta práctica social está en la naturaleza, entonces difícilmente podrá ser definida como una institución y, por tanto, interpelada socialmente. La idea difusa que envuelve el fenómeno de la prostitución es que está más allá de lo cultural. Aparece como una realidad que transita entre lo natural y lo social. De ahí que se repita incansablemente que la prostitución ha existido siempre, como si ese fuese un argumento irrefutable. Sin embargo, la prostitución no es el oficio más antiguo del mundo sino la actividad que responde a la demanda más antigua del mundo: la de un hombre que quiere acceder al cuerpo de una mujer y lo logra a cambio de un precio (Fernández Oliver, 2007: 89).

Eso sí, para justificar que la prostitución es una realidad natural hay que afirmar que se inscribe en el orden de la sexualidad humana. El subtexto, por tanto, alude a que la 
sexualidad masculina es incontrolable y, por ello, la femenina debe estar al servicio de ese deseo masculino irrefrenable, a través de la prostitución o del matrimonio. Si la prostitución hunde sus raíces en la sexualidad, entonces no es posible erradicarla. La legitimación de la prostitución parte tácitamente de la sexualidad masculina como pulsión imposible de gestionar culturalmente. Señala Carole Pateman que la legitimación de la prostitución se origina en el estereotipo de la urgencia sexual natural de los varones: "Existe un impulso masculino natural y universal que requiere y siempre requerirá de la prostitución para su satisfacción” (Pateman, 1995: 273).

Para concluir este apartado es preciso hacer dos reflexiones: la primera gira en torno a la pregunta de quién fabrica estas narraciones. Las teorías críticas de la sociedad ${ }^{1}$ ya han explicado la estrecha relación entre los relatos sociales y las estructuras de poder. Los relatos, por tener como una de sus finalidades la legitimación de los entramados sociales e institucionales, se fabrican en función de los intereses y necesidades de las élites y de los grupos dominantes. En otros términos, las élites masculinas y neoliberales han propuesto a la conciencia de nuestra época la idea de que la actividad prostitucional es tan legítima como otras actividades. Y las instancias socializadoras de estos sistemas de poder han contribuido a su normalización. Y la segunda es que la naturalización de la prostitución se inscribe en un discurso mucho más amplio que ha tenido lugar en las últimas décadas del siglo XX y los comienzos del siglo XXI, al hilo de la globalización neoliberal: la naturalización de la desigualdad. Por eso, argumentaré a lo largo de este trabajo que no es lo mismo decir que la prostitución es un trabajo libre que decir que es una forma de subordinación patriarcal. Y añadiré que también es una forma de explotación económica al extremo de convertirse en una de las nuevas formas de servidumbre del siglo XXI. En palabras de Carole Pateman: "la prostitución es parte integral del capitalismo patriarcal" (Pateman, 1995: 260).

\section{De la cultura del sexo a la cultura de la prostitución}

En este apartado argumentaré que la formación de una 'cultura de la prostitución' (Jeffreys, 2002) ha discurrido al mismo tiempo que la construcción de una poderosa cultura del sexo. La condición de posibilidad de que se pueda configurar una cultura de la prostitución es que exista una cultura de la sexualidad que articule la identidad de las mujeres alrededor de su disponibilidad sexual. Ambas culturas, funcionalmente vinculadas, ejercen una influencia decisiva en la formación de las normatividades masculina y femenina. En efecto, las representaciones de las mujeres en los medios de comunicación, el papel de la moda, la pornografía o la prostitución contribuyen a moldear el significado social de las normatividades de género. Y, además, el aumento y la normalización de la industria del sexo contribuyen a restaurar los códigos de la feminidad y la masculinidad más hegemónicamente patriarcales al tiempo que

${ }^{1}$ Utilizo el término teoría crítica en el sentido en que la describe Nancy Fraser: "queremos una teoría del discurso que pueda aclarar cómo la hegemonía cultural de los grupos dominantes en una sociedad se asegura y se enfrenta" y "la teoría debería iluminar las perspectivas de cambio social emancipatorio y de práctica política” (Fraser, 1991: 14). 
fortalecen, la ideología de la misoginia. Por todo ello, es preciso reflexionar sobre los elementos que cooperan activamente en la formación de ambas culturas.

Esta propuesta de normatividad femenina, sobrecargada de sexualidad, pone de manifiesto el reactivo cambio cultural que se ha producido en las sociedades occidentales tras el éxito del feminismo radical de los años setenta (Cobo: 2015). En nuestro entorno cultural ha cobrado fuerza la idea de que las mujeres deben ser valoradas fundamentalmente por su atractivo sexual. El proceso de creciente objetualización de los cuerpos de las mujeres forma parte de este nuevo ideal de feminidad que proponen las sociedades patriarcales a una parte de las mujeres. El atractivo sexual se ha convertido en parte fundamental del nuevo modelo normativo que se exige a adolescentes y mujeres adultas. Natasha Walter lo explica de esta forma: "Las imágenes sexualizadas de las mujeres jóvenes amenazan con borrar de la cultura popular cualquier otro tipo de representación femenina" (Walter, 2010: 91).

Sin embargo, este modelo, cada vez más hegemónico, coexiste con otro, desarrollado por reducidos grupos de mujeres, que pueden elegir opciones laborales, profesionales y sentimentales ajenas a esta cultura de la hipersexualización. En efecto, este modelo de normatividad femenina, a pesar de que se dirige a todas las mujeres, pesa mucho más en aquellas jóvenes que tienen pocas posibilidades de elegir. Richard Poulin explica que la mercantilización de los cuerpos y los sexos afecta sobre todo a los más vulnerables de la sociedad, pues tiene un carácter marcadamente clasista y/o étnico (Poulin, 2005). En efecto, la sexualización es un rasgo que los sistemas de dominio asignan a los miembros de los colectivos oprimidos. El subtexto de esta asignación es que quien está marcado por el sexo está más próximo a la naturaleza que a la cultura, más al instinto que a la racionalidad. Mientras que la razón ha sido un atributo masculino, los sentimientos y la sexualidad se han prescrito como las características determinantes de las mujeres. En el caso de la prostitución y la pornografía se observa la intensificación de este dispositivo, pues se sobresexualiza a aquellas mujeres que el Occidente etnocéntrico ha designado como pertenecientes a culturas inferiores. Dicho en otros términos, la pornografía y la prostitución añaden un plus de sexualización a las mujeres de otras razas: las sobreracializa y las sobre-sexualiza.

La sexualización de las mujeres es un dispositivo central en la construcción de la normatividad femenina. Tiene un carácter prescriptivo y por ello mismo, también ontológico, pues debe ser presentado como un rasgo natural de las mujeres. Uno de los subtextos de la sexualización de las mujeres es situarlas simbólicamente más cerca de la naturaleza que de la cultura. Sin embargo, la ontología está precedida por la política. Primero es la subordinación social y política y después, para legitimar esa opresión, se fabrica una naturaleza inferior. Y así se puede dar la vuelta al argumento: la posición de inferioridad social tiene su origen en los déficits ontológicos de los grupos oprimidos. Este mecanismo de inferiorización se ha utilizado habitualmente con los colectivos oprimidos y especialmente con las mujeres, a las que la cultura patriarcal ha sobrecargado de sexualidad. A pesar de que las mujeres han soportado una sobrecarga de sexualidad en las sociedades patriarcales, en estas últimas décadas, tras el éxito del feminismo radical de los años setenta, sobrevino inesperadamente una resaca reactiva y con ella una operación de re-sexualización de las mujeres. Y esta redefinición de las 
mujeres en términos de su sexualidad está directamente vinculada a la cultura del sexo y de la prostitución. Poulin lo explica así: "En las revistas femeninas y para adolescentes abundan amables reportajes sobre estrellas del porno, sobre personas prostituidas felices de estar en la industria del sexo. Los artilugios que se venden en las sex-shops son probados y son objeto de promoción. Para sentirse bien con su vida, las mujeres y las adolescentes deben adoptar nuevas prácticas sexuales y usar los productos que dicta la industria del sexo. Es necesario que lo prueben todo y que aprendan a disfrutar de la sodomía, la eyaculación facial o la triple penetración" (Poulin, 2009). De hecho, la pornografía es representada como una industria de la 'fantasía sexual' en los medios de comunicación, en la moda e incluso en la literatura. La objetualización del cuerpo de las mujeres y la banalización de la sexualidad se han convertido en parte de la cultura popular. Peter Szil explica las consecuencias de esta cultura: "La conversión de las mujeres en objetos sexuales es un proceso de deshumanización en cuyo extremo final está la violencia sexual masculina. Es esto lo que la prostitución institucionaliza, ya que el cliente consigue de la persona prostituida (que no ha elegido hacer el amor con él) algo que de otra manera no podría conseguir sino con violencia. El cliente (y con él la sociedad) oculta ante sí mismo el hecho de la violencia interponiendo una infraestructura (manejada por los proxenetas) y el dinero" (Szil, 2007:84-89).

A modo de conclusión, hay que señalar que la cultura de la prostitución se ha edificado sobre una cultura del sexo que ha colonizado el imaginario colectivo. La hipersexualización de lo femenino es un componente esencial de esta ideología que intenta reducir a las mujeres a sexualidad. En las tres últimas décadas, los medios de comunicación avanzan inexorablemente en la producción de imágenes de mujeres hipersexualizadas. La imagen dominante de la sexualidad femenina que se está reelaborando muestra a las mujeres como cuerpos: "la nueva cultura hipersexual redefine el éxito femenino dentro del reducido marco del atractivo sexual" (Walter, 2010: 23). Y, a su vez, esta cultura del sexo contribuye a normalizar la prostitución como práctica y como cultura. La existencia de ambas culturas, la del sexo y la de la prostitución, es resultado de la dominación masculina.

\section{Economía política de la prostitución}

La prostitución es una práctica social que hace posible que los varones obtengan sexo a cambio de dinero. Carole Pateman explica que la prostitución es parte fundamental del contrato sexual, en el sentido de que es una de las dos formas, junto al matrimonio, en que los varones se aseguran el acceso sexual al cuerpo de las mujeres (Pateman, 1995: 267). En efecto, los demandantes son varones y quienes ejercen la prostitución son mujeres. Sin embargo, lo nuevo de la prostitución es que ahora forma parte de una industria internacional del sexo que incluye una gran variedad de negocios, desde macroburdeles o locales de striptease hasta libros, películas o revistas sobre pornografía, sin olvidarnos del turismo sexual. Los cuerpos de las mujeres se han convertido en las mercancías sobre las que se ha edificado una industria global. Por eso, Sheyla Jeffreys considera que la prostitución debe ser explicada en el marco de la economía política (Jeffreys, 2011: 11). 
Sin embargo, no solo se ha transformado materialmente esta práctica social sino también la ideología que la envuelve, pues el crecimiento de la industria del sexo como una gran 'empresa' global está modificando el viejo imaginario que existía sobre la prostitución. En efecto, a medida que la prostitución ha dejado de ser un pequeño negocio y se ha transformado en una gran 'industria', de la mano de las políticas económicas neoliberales, esta práctica ha ido ganando cada vez más presencia social. Hace simplemente tres décadas la prostitución era un conjunto de burdeles con mujeres autóctonas que ejercían la prostitución con encargadas y jefas que gestionaban, a veces paternalistamente, esos pequeños negocios: “Antes existían muchos 'clubes de alterne' pequeños. Eran lugares íntimos, casi familiares. Ahora quedan cada vez menos, y los que quedan han vivido una transformación radical, tanto en la forma como en la manera de funcionar. Los pequeños clubes, en su mayoría, están desapareciendo, sustituidos por los megalocales de striptease con showgirls y chicas exhibiéndose con la mínima ropa posible. Son negocios que a veces incluso funcionan con licencia de hotel... Los pequeños locales donde tantas mujeres ejercían de manera más o menos discreta una forma de prostitución light, porque no solamente no estabas obligada a acostarte con los clientes, sino que además podías ganar mucho dinero sin necesidad de ello, son ya cosa del pasado" (De León, 2012: 71). En esa antigua forma de prostitución no existían mujeres migrantes ni tráfico de mujeres en los circuitos migratorios ni en los circuitos criminales. En otros términos, ese viejo canon de la prostitución no daba cuenta de la gran industria del sexo que existe en la actualidad.

El nuevo capitalismo ha hecho posible la transformación de la prostitución en una gran industria interconectada en forma de red, vinculada a la economía criminal y con poderosos brazos en otros sectores económicos (Castells, 1998: 204). En efecto, es prácticamente imposible encontrar burdeles o macroburdeles que en algún punto de su actividad empresarial no estén vinculados a la economía criminal, desde el tráfico de mujeres hasta el blanqueo de capitales. La 'materia prima' de esa industria son los cuerpos de las mujeres, que se han convertido en una mercancía que reúne las dos condiciones necesarias de la globalización neoliberal: negocio de bajo riesgo y altos rendimientos. Seyla Jeffreys explica que varias fuerzas se han conjugado para dar nueva vida a esta práctica social: "Lo más importante es la nueva ideología y práctica económica de estos tiempos neoliberales en los que la tolerancia de la 'libertad sexual' converge con la ideología del libre mercado para reconstruir a la prostitución como 'trabajo' legítimo que funciona como base de la industria del sexo, tanto a nivel nacional como internacional" (Jefffreys, 2011: 12).

La transformación de la prostitución en un negocio global se debe a la existencia de los 'mercados desarraigados' (Fraser, 2012), sin regulación estatal ni control social, y cuya lógica económica depredadora ha mercantilizado no sólo la naturaleza, el dinero y el trabajo si no también los cuerpos y la sexualidad de las mujeres. El objetivo es que las mujeres se conviertan en una forma de consumo más: "reducir a las mujeres prostituidas a objetos mercantiles" (Paris, 2012: 60).

Saskia Sassen señala que la nueva economía capitalista está promoviendo con sus políticas neoliberales el surgimiento de unas nuevas clases de servidumbre. Mujeres e inmigrantes, entre las que podemos identificar a las mujeres prostituidas, constituyen el 
núcleo fuerte de esas nuevas servidumbres (Sassen, 2003: 80). El tráfico ilegal de mujeres para la industria del sexo está aumentando como fuente de ingresos y las mujeres se han configurado como el grupo de mayor importancia en los sectores de la prostitución y la industria del sexo y se están convirtiendo en un grupo mayoritario en la migración orientada a la búsqueda de empleo. Las mujeres prostituidas, mayoritariamente, pertenecen a las clases más depauperadas y empobrecidas y, por tanto, con necesidades económicas extremas. Muchas de estas mujeres pertenecen a regiones del mundo con altos niveles de pobreza y con culturas marcadas por el desprecio a las mujeres. Además, en los países con altos niveles de bienestar, la prostitución se plantea como una de las pocas salidas económicas disponibles para mujeres inmigrantes en situación irregular. También existen excepcionalmente algunas mujeres que, sin ser inmigrantes ni extremadamente pobres, buscan una mejora de su situación a través de la obtención del dinero rápido que la prostitución puede llegar a proporcionar.

La prostitución se está configurando como un elemento fundamental para el desarrollo. Sassen explica que las mujeres entran en el macronivel de las estrategias del desarrollo básicamente a través de la industria del sexo y del espectáculo y a través de las remesas de dinero que envían a sus países de origen. La exportación de trabajadores y trabajadoras y las remesas de dinero son herramientas de los gobiernos de países con altos niveles de pobreza para amortiguar el desempleo y la deuda externa. Y ambas estrategias tienen cierto grado de institucionalización de los que dependen cada vez más los gobiernos.

El alto desempleo, la pobreza, el estrechamiento de los recursos del estado en cuanto a necesidades sociales y la quiebra de un gran número de empresas hacen posible la existencia de una serie de circuitos con un relativo grado de institucionalización por los que transitan sobre todo las mujeres. Por esos circuitos, precisamente, circulan mujeres para el trabajo doméstico y la prostitución. Y por esos circuitos se introducen también los traficantes de personas y las mafias vinculadas al tráfico de mujeres. Al mismo tiempo, esos circuitos adquieren cierto grado de institucionalización porque el Banco Mundial y el Fondo Monetario Internacional exigen a los países endeudados que edifiquen una industria del ocio y del espectáculo que haga posible el pago de la deuda (Jeffreys: 2011; Sassen: 2013). Pues bien, la prostitución infantil y adulta es una parte fundamental de este sector económico que, a su vez, se configura como una estrategia de desarrollo de los países con altos niveles de pobreza. Y muy particularmente es una fuente de desarrollo económico rural para las regiones pobres (Barry, 1991: 71). En otros términos, la prostitución, como fenómeno social global, no puede ser comprendida si no mostramos la relación entre desigualdad económica, inmigración y estructuras de poder patriarcales.

La existencia de esos circuitos semi-institucionalizados pone de manifiesto que la prostitución no crece espontáneamente. Se ha creado un clima ideológico, social e institucional que promueve el desarrollo de esta práctica social. De hecho, durante los años sesenta, en Tailandia, el ministro del Interior defendió públicamente la expansión de la industria del sexo para promover el turismo y facilitar el despegue económico del país. El número de visitantes extranjeros -el turismo sexual- a Tailandia pasó de 2 millones en 1981 a 7 millones en 1996 (Bales, 2000: 83-84). El gobierno coreano estimó que la prostitución en 2002 representó el 4,4\% del PIB. Y la industria del sexo en 
Holanda, legalizada en 2001, representaba el 5\% del PIB. En China se estima que esta industria constituye un $8 \%$ de su economía. Y el aumento del 12\% en las ganancias de Chivas Regal en 2004 fue atribuido, en un informe, a su asociación con los prostíbulos tailandeses (Jeffreys, 2011: 15-17).

Asimismo, la prostitución es el máximo exponente de la deslocalización neoliberal, pues las mujeres son trasladadas de los países con altos niveles de pobreza a los países con más bienestar social para que los varones demandantes con suficientes recursos económicos accedan sexualmente a los cuerpos de esas mujeres. La prostitución es un negocio global interconectado en el que las mafias de la economía criminal controlan todo el proceso, desde la captación de adolescentes y mujeres en sus países de origen hasta su inserción en los clubs de alterne de los países de destino. Si bien el cuerpo de la mujer prostituida siempre ha sido una mercancía, en esta época de globalización neoliberal, marcada por un feroz individualismo posesivo, el cuerpo de las mujeres prostituidas se convierte en una mercancía muy codiciada por los traficantes y pronexetas porque proporciona altos beneficios con bajos costes (Policía Judicial, 2005).

La globalización de la industria del sexo hace que los cuerpos de las mujeres, como negocio, ya no permanezcan dentro de los límites del estado-nación: "El tráfico, el turismo sexual y el negocio de las esposas que se compran por correo han asegurado que la severa desigualdad de las mujeres pueda ser transferida más allá de las fronteras nacionales de manera tal que las mujeres de los países pobres puedan ser compradas con fines sexuales por hombres de los países ricos. El siglo XX vio el hecho de que los países ricos prostituyen a las mujeres de los países pobres como una nueva forma de colonialismo sexual" (Jeffreys, 2011: 17).

Por otra parte, la legalización de la prostitución en algunos países y la casi absoluta libertad de mercado están ampliando los límites de la industria del sexo. Y este hecho coloca a niñas, adolescentes y mujeres de regiones del mundo con elevadas tasas de pobreza, con una cultura de desprecio a las mujeres y con el deseo de aumentar el consumo familiar, en una situación de 'entrega y venta' a las redes de tráfico, tal y como afirma Kevin Bales, refiriéndose a Tailandia (Bales, 2000: 39-87). La globalización neoliberal y la ausencia de controles al mercado por parte de los estados ha hecho posible el crecimiento de la industria del sexo y ha facilitado el desarrollo de la economía criminal. La suma de estos factores hace que millones de niñas y mujeres se conviertan en mercancías para esta industria y para el uso sexual de varones de todo el mundo.

\section{El papel de los varones en la prostitución}

Las investigaciones que se han realizado sobre la prostitución se centran fundamentalmente en la figura de la mujer prostituida. Se ha ido configurando un imaginario de la prostitución en el que la figura de la puta lo ocupa por completo: "Casi todas las investigaciones acerca de la prostitución eluden detenerse en aquellos que la consumen. Son estudios que, al tiempo que estudian el fenómeno y lo denuncian, tienden a proteger con un manto de inocencia a los usuarios" (Díez, 2012: 4). Y, como sabemos, los imaginarios contribuyen a la formación de las definiciones sociales. Y, también sabemos que no existe prostituta sin varón demandante. 
¿Por qué el varón ha sido invisibilizado en el imaginario de la prostitución? Hay que hacer notar que la figura del varón demandante ha sido invisibilizada como si fuese un elemento completamente secundario en esta realidad social. Y este hecho es un claro indicador de la permisividad social que existe hacia los varones consumidores de prostitución. Por eso es necesario reconstruir equilibradamente el imaginario de la prostitución y poner a los demandantes en el lugar que les corresponde, pues esos varones son algo más que meros consumidores de sexo. En efecto, tienen su cuota de responsabilidad en la violencia que produce la prostitución y en la existencia de una industria que cosifica, explota y subordina a millones de mujeres en todo el mundo.

En efecto, la prostitución no es una práctica social inocua sino que, como todas las demás, no puede sustraerse a las relaciones de poder que estructuran cada sociedad. Sin embargo, se oculta la asociación entre demandante y dominio masculino para así enmascarar las relaciones de poder que están en la base de la prostitución. De ahí la necesidad de mostrar el vínculo entre demandantes y dominio masculino y de resignificar el imaginario de la prostitución y redefinir a los demandantes como prostituidores. El hecho de que los varones tengan el control de la mayoría de los recursos debe servir para iluminar la existencia social de esta institución que estamos examinando. En sociedades en las que los varones tienen una posición de hegemonía, difícilmente podría pensarse que la prostitución es una realidad ajena a las relaciones de poder entre los géneros. No se puede obviar la realidad de que la práctica totalidad de las personas que ejercen la prostitución son mujeres y la práctica totalidad de los que usan sexualmente los cuerpos de esas mujeres son varones. También es imprescindible tener en cuenta que el control de las redes de tráfico de mujeres y la propiedad de los negocios que conforman la industria del sexo está en manos masculinas. La prostitución, como práctica social, no puede ser aprehendida si no se colocan en el centro del análisis las estructuras patriarcales.

Si bien he argumentado que la prostitución no puede entenderse fuera del marco del nuevo capitalismo, es necesario buscar otras variables explicativas. El neoliberalismo, con su propuesta de mercantilización y privatización de todo aquello susceptible de proporcionar beneficios, ha hecho posible el crecimiento de la industria del sexo hasta el extremo de su conversión en una de las mayores fuentes globales de ingresos. Sin embargo, este crecimiento de la prostitución no puede obviar la necesidad de buscar explicaciones tanto en la estructura patriarcal como en la conducta de los usuarios de esta práctica social. Y una de ellas puede encontrarse en la crisis del modelo masculino tradicional. La mayor presencia en nuestra cultura de la ideología de la igualdad entre hombres y mujeres, impulsada por el feminismo radical de los años setenta, modificó el papel de las mujeres en muchas sociedades. Por un lado, aumentó su margen de libertad y autonomía, así como su capacidad de negociación con los varones en sus relaciones de pareja en el ámbito privado-doméstico; pero también se hizo significativa su presencia en el mercado laboral y en el ámbito público-político, pese a su presencia aún reducida. El proyecto emancipador que supuso el feminismo radical tuvo efectos sobre grupos de mujeres en distintas sociedades y obligó a los varones a compartir su papel de proveedores en la familia y a compartir, aun en una pequeña parte, los espacios de decisión y poder en los espacios públicos. Esto ha supuesto no sólo un cambio cultural 
importante en las formas de relacionarse los varones con las mujeres sino que también ha movilizado resistencias pacíficas y violentas por parte de aquellos que no aceptaban un nuevo estatus de menor poder. En este cambio cultural y en las resistencias a ese cambio puede hacerse legible en la conducta de algunos varones un desplazamiento del dominio masculino del ámbito familiar y de pareja hacia la prostitución, pues esta práctica confirma el antiguo rol de autoridad y dominación masculina en el que está exenta la negociación. En la prostitución la sexualidad tradicionalmente hegemónica masculina encuentra un espacio en el que puede desarrollarse. La lucha del feminismo radical por democratizar la familia y distribuir paritariamente el poder entre los miembros de la pareja parece ser compensado a través del ejercicio de la práctica prostitucional en la que la negociación es sustituida por el dominio y el control masculino. Los varones que no aceptan la igualdad encuentran en la prostitución su hábitat natural.

El crecimiento de la prostitución está relacionado con dos procesos sociales que están transformando el mundo del siglo XXI y estrechamente vinculados a la crisis del contrato sexual. Mujeres en distintas partes del mundo han conseguido derechos $\mathrm{y}$, además, los han ejercido, pues por primera vez en la historia, grupos reducidos, pero significativos, de mujeres pueden decir, y dicen, 'no' a los varones. Esa primera parte del contrato sexual por el que cada varón se convierte en dueño y señor de una mujer, y cuya expresión social legítima es el matrimonio, ha entrado en crisis, pues ha dejado de ser la única opción para muchas mujeres. Sin embargo, este hecho no debe oscurecer que frente a esta mayor libertad para algunas mujeres, se encuentran otras cuya situación ha empeorado visiblemente. Y con esta afirmación, me estoy refiriendo a la segunda parte del contrato sexual, por la que un reducido grupo de mujeres es asignado a todos los varones y cuya expresión es la prostitución. En otros términos, a medida que algunas mujeres pueden desasirse del dominio masculino y conquistan parcelas de individualidad, otras son más intensamente dominadas y explotadas por el sistema patriarcal.

Pascal Bruckner y Alain Finkielkraut (1979) ponen el acento en el hecho de que la prostitución femenina es cómoda para los hombres porque acceden de modo inmediato al sexo y ahorran tiempo, se saltan los pasos del cortejo, prescinden de la interacción personal, el trabajo de seducción y el miedo al rechazo. Por eso, la prostitución se convierte en una opción rápida y eficaz para aquellos que no desean hacer el esfuerzo de entablar contacto con mujeres que al final de la noche quizá se negarán a mantener relaciones sexuales. También señalan que otra ventaja es que pueden despreocuparse por completo del placer de la otra persona y centrarse en el suyo, porque la prostituta no protestará. Al contrario que los amantes, las prostitutas desean que el cliente llegue al orgasmo cuanto antes: así podrán ofrecer más servicios en menos tiempo. Prostitución y dominio masculino, como sugiere la argumentación de Bruckner y Finkielkraut, son realidades inseparables.

Sin embargo, no es así en el caso de las mujeres que ejercen la prostitución. Estas mujeres no sienten placer ni gratificación por la realización de esta práctica. Estos autores explican que la prostituta no es un cuerpo que goza sino un cuerpo que trabaja. La mujer prostituida representa un personaje concreto en una obra concreta escrita por los clientes, a la que se exige que silencie sus caprichos y sus deseos, a no ser que se 
le pida lo contrario (Bruckner y Finkielkraut 1979). En efecto, las mujeres, en tanto objetos para los varones, no tienen sexualidad propia. Están destinadas únicamente, tal y como señala Carlos Paris, a "satisfacer la sexualidad imperativa del animal masculino" (Paris, 2012:61).

Las mujeres prostituidas se convierten en una forma de diversión que practican los varones, a veces solos y a veces en grupo. De la misma forma, los negocios empresariales a menudo incluyen sexo como premio a quienes han hecho posible y/o facilitado la firma del contrato. El ocio y el descanso tienen también en el turismo sexual una de sus manifestaciones. Así, los varones confirman el contrato sexual, su posición de poder y su masculinidad en la prostitución. Esta práctica opera como una reactualización del pacto masculino para asegurarse el acceso sexual al cuerpo de las mujeres.

Peter Szil (2007) aporta una tesis certera respecto a los varones demandantes de prostitución: "En la prostitución (al igual que en el caso de las violaciones de grupo o las violaciones masivas en situaciones de guerra) los hombres utilizan los cuerpos de las mujeres para comunicarse entre ellos mismos y para expresar lo que les une, y que al fin y al cabo se reduce a que ellos no son mujeres. Lo que hace posible, entre otras cosas, para un hombre encontrar una prostituta es el hecho de que antes de él ya había otros hombres que han acudido a ella, y detrás de él habrá otros. De esta manera se convierte el cuerpo de la mujer prostituida (al igual que el de la mujer violada) en ese agente transmisor a través del cual los hombres comparten entre ellos mismos, en palabras y en hechos, su sexualidad. No es por casualidad que muchos hombres al maltratar a su pareja acompañen los golpes y las patadas con sinónimos groseros de la palabra 'puta' (Szil, 2007). Szil apunta a la cuestión fundamental: al contrato sexual. En este contrato, las mujeres se convierten en mediadoras simbólicas de los varones. La prostitución es una realidad social que contribuye a reforzar las 'afiliaciones horizontales' entre los varones. Por eso, esta institución actúa como un dispositivo simbólico que devuelve a los varones la imagen de un grupo de iguales en el que la mediación simbólica de esa igualdad es la 'puta'.

\section{Consentimiento y coacción en la prostitución}

Un argumento que aparece recurrentemente en la literatura sobre prostitución y que está muy asentado en el imaginario colectivo es el de la legitimidad de la relación entre la mujer prostituida y el varón demandante, siempre y cuando las mujeres elijan libremente esa actividad (Gimeno, 2012). Sin embargo, ¿hasta qué punto las mujeres prostituidas, todas ellas pobres y en algunos países, además, inmigrantes, muchas de ellas en situación irregular, y empujadas a transitar por esos circuitos semi-institucionalizados, pueden ser definidas como libres a la hora de elegir la prostitución como forma de vida? Con esta pregunta, queremos advertir que la cuestión del consentimiento es una variable fundamental a la hora de adoptar una posición ética-normativa sobre la prostitución.

¿Es un contrato libre, y por ello legítimo, el que establecen la mujer prostituida y el varón demandante? Para contestar esta pregunta es necesario volver los ojos al intenso debate político que tuvo lugar en el siglo XVIII, en el contexto de la Ilustración. La Modernidad se edificó sobre una nueva relación social, la contractual, y la piedra 
angular de ese edificio fue el consentimiento. La figura del individuo como sujeto político, la configuración de una nueva clase hegemónica, la burguesía, y la propuesta de un nuevo sistema político, la democracia, son los elementos centrales del nuevo mundo que se gestó a partir del siglo XVIII en Occidente. Y es ahí, precisamente, donde adquiere sentido la categoría de consentimiento. La Modernidad no aceptará la instauración de sistemas políticos ni relaciones sociales que no estén basados en un contrato basado en el libre consentimiento de sus miembros. No podríamos entender la democracia ni el resto de las relaciones sociales, incluido el matrimonio, fuera del contrato, no solo en Occidente sino también en otras regiones del mundo. Ese tipo de relación contractual es históricamente nueva y surge como una conquista frente a las relaciones sociales medievales, basadas en relaciones de adscripción.

A fin de comprender las relaciones sociales que se desarrollan entre el varón demandante y la mujer prostituida es necesario hacer una reflexión sobre la naturaleza del contrato y sobre la naturaleza del consentimiento. Locke mantenía que la libertad de los individuos debe tener un carácter tan absoluto que un individuo puede decretar su propia esclavitud hasta el extremo de firmar un contrato libremente con su esclavizador. La clave de la legitimidad de este contrato para Locke está en la voluntad del individuo que decide esclavizarse. Sobre este supuesto reposa el liberalismo: sobre la absoluta libertad del individuo.

Algunos años después, Rousseau, uno de los teóricos más críticos de la desigualdad económica y un referente ideológico para los movimientos sociales críticos, polemizaba con Locke en el sentido de afirmar que si un individuo decreta su propia esclavitud pierde su condición de humanidad. Es decir, la libertad es un atributo inherente de la condición humana. La clave en este razonamiento, pues, es la libertad. Tal y como señalaba Rousseau, un contrato firmado por dos partes en la que una está dominada por la necesidad no es un contrato legítimo, puede ser legal, pero nunca será legítimo. Lo que el filósofo ginebrino no decía explícitamente, pero se ha teorizado desde la teoría crítica es que este tipo de contrato sanciona una relación social de dominación y de subordinación (Cobo, 1995).

Kant también explica que no se puede ser al mismo tiempo cosa y persona, propiedad y propietario (Posada, 2015: 95). Estos filósofos sugieren que esos contratos podrán ser legales, pero nunca legítimos porque la capacidad de decisión de quien está dominado por la necesidad vicia ese consentimiento. En esa misma línea, en el siglo XIX, Marx lanzaba una mirada crítica a los contratos establecidos entre un burgués y un obrero, entre un empresario y un trabajador, al poner en cuestión los contratos económicos basados en la necesidad absoluta de una de las partes contratantes. Y de esta argumentación se deriva una conclusión que ha estado en el fundamento de todas las teorías críticas de la sociedad: no puede haber libertad de contrato absoluto en sistemas sociales edificados sobre dominaciones. Ya en el siglo XX, Carole Pateman analiza el contrato entre demandante y mujer prostituida como carente de legitimidad, pues esa relación se origina en un contrato sexual sobre el que se edifican los sistemas de poder patriarcales.

El argumento que quiero señalar es que la ilimitada libertad de contrato forma parte del núcleo ideológico más duro del liberalismo y la crítica a esa libertad absoluta forma 
parte de las señas de identidad ideológicas de los pensamientos críticos. En efecto, la libertad y el consentimiento de las mujeres que llegan a la prostitución son reducidos, pues están limitados por la pobreza, la falta de recursos culturales, la escasa autonomía y en muchos casos por el abuso sexual en la infancia. Y para que todo ello adquiera sentido hay que señalar que esas realidades están inscritas en el marco de sociedades patriarcales en las que los varones tienen una posición de hegemonía sobre las mujeres. Aceptar la prostitución como un trabajo solo es posible si se prescinde de la idea del dominio patriarcal.

Los análisis que intentan argumentar la prostitución como un contrato legítimo se apoyan en argumentaciones funcionales al neoliberalismo, para cuya ideología los contratos no deben tener límites. Los autores y autoras que defienden la legitimidad de ese contrato fundamentándolo en la voluntad del individuo, se olvidan que libertad y voluntad no suelen coincidir en los sistemas de dominio, pues "la libertad no es negociar lo que es inevitable en una situación dada, sino la capacidad de transformar radicalmente la situación y/o determinarla" (Jeffreys, 2011: 39). En consonancia con este argumento, hay que señalar como un factor relevante la significativa desigualdad económica entre la población prostituida y la población demandante (Vigil y Vicente, 2006). Esta desigualdad económica es un elemento fundamental para calibrar el grado de consentimiento que existe en estas relaciones, pues más del $90 \%$ de las mujeres prostituidas en Europa son inmigrantes (Fondation Scelles: 2012).

\section{Reflexiones finales}

El feminismo es un proyecto político de transformación social y cualquier proyecto de cambio social abriga en su interior un impulso ético-normativo. Esa dimensión crítico-normativa del feminismo es la que muestra la prostitución como una práctica de poder patriarcal, capitalista y racial/cultural. La prostitución es un efecto directo del contrato sexual, sobre el que se han edificado las estructuras patriarcales. Por ello mismo, reproduce y fortalece la jerarquía de género. Además, no puede olvidarse que la industria de la prostitución está en manos masculinas, mientras que los cuerpos de las mujeres, la mercancía de la que se nutre la industria del sexo, es femenina. La posición que he querido argumentar en este trabajo es que la prostitución no es una actividad económica contractual entre mujer prostituida y varón demandante sino una relación de poder y explotación sexual. Desde este punto de vista, la prostitución es una práctica social que se inscribe en el dominio patriarcal.

En este sentido es necesario retomar las categorías de patriarcado y de contrato sexual, pues sin estos conceptos no podríamos articular la posición ético-normativa que hemos mantenido en este texto sobre la prostitución. Como hemos señalado, la prostitución es una de las formas de distribución de las mujeres por parte del genérico masculino. El matrimonio y la prostitución se configuran, tal y como explica Pateman (1985), en las dos instituciones de regulación de la sexualidad y a través de ambas pueden los varones acceder sexualmente al cuerpo de las mujeres. Solo se hace legible la prostitución a la luz de esta doble estructura sistémica sobre la que se asienta la hegemonía masculina. 
Es, precisamente, el hecho de que en la prostitución se encuentren tres dominaciones distintas lo que hace necesario que los pensamientos críticos se hagan cargo teórica y políticamente de la prostitución y expliquen su incremento como resultado de la depredación de los mercados. La extensión de la prostitución y su conversión en un negocio global es un efecto directo de la falta de límites del capitalismo actual. Con esto no estoy sosteniendo que el problema de la prostitución deba ser analizado solo en el marco del nuevo capitalismo. Como ya he señalado, la prostitución es una institución patriarcal, que en el último tercio del siglo $\mathrm{XX}$ ha sido transformada en un sector económico pujante en el que millones de mujeres han sido convertidas en mercancías y en el que los dueños del entramado económico de la industria del sexo son varones.

El fenómeno de la prostitución muestra a las mujeres como 'las idénticas', siguiendo el análisis de Celia Amorós. En efecto, la identidad es el destino que las sociedades patriarcales prescriben para las mujeres con el objetivo de que esas sociedades puedan garantizar el dominio masculino. La igualdad es asignada en los albores de la modernidad a los varones y la identidad a las mujeres. Y ambos atributos en sí mismos son excluyentes. La igualdad implica autonomía, libertad, margen de maniobra para elegir y la posibilidad de diseñar tu propio proyecto de vida. La identidad, por el contrario, es una atribución que incluye los elementos que configuran la normatividad femenina, tal y como ha sido definida patriarcalmente: uso de su sexualidad para satisfacción del varón y subordinación al marido o demandante; silenciamiento del propio deseo y sumisión al deseo masculino. En definitiva, las sociedades patriarcales exigen a las mujeres que acepten su existencia como cuerpos y como sexualidad, con el objetivo de dedicarse a la reproducción o a la prostitución. Una condición de posibilidad de la identidad es la ausencia de individualidad, entendida esta como autonomía. Las 'idénticas' carecen de individualidad. Por eso, en los varones pesa más la humanidad y en las mujeres, la feminidad; en los varones, la racionalidad y en las mujeres, la sexualidad. En conclusión, el mundo de los varones es el de la trascendencia y el de las mujeres, el de la inmanencia, tal y como nos explicará Simone de Beauvoir.

Las mujeres prostituidas son despojadas de cualquier singularidad y se presentan completamente despersonalizadas. Su valor para la prostitución nada tiene que ver con sus sentimientos o con su inteligencia. Solo el cuerpo es el objeto de interés masculino. El mandato patriarcal es que sean idénticas: cuerpos hipersexualizados, que deben repetir clónicamente gestos y movimientos al servicio del placer sexual masculino. Como explica Carmen Vigil, "para el cliente, las prostitutas son simplemente cuerpos femeninos en abstracto. Cualquier prostituta es intercambiable por otra y el único criterio de elección posible entre una y otra son sus características anatómicas. El cliente elige entre cuerpos, no entre personas" (Vigil y Vicente, 2006). Desde este análisis, la prostitución puede verse como la metáfora perfecta de la negación del principio de individuación, pues el ejercicio de la individualidad se traduce en derechos, vinculados a la autonomía y libertad. La prostitución, por tanto, como institución patriarcal, afirma la identidad y niega la individuación y la igualdad. 


\section{Bibliografía}

Bales, K. (2000): La nueva esclavitud en la economía global, Madrid, Siglo XXI.

Berger, P. L. (1981): Para una teoría sociológica de la religión. El dosel sagrado, Barcelona, Kairós.

Barry, K. (1991): "Prostitución y victimización. La mujer ausente: derechos humanos en el mundo", Isis Internacional, Santiago de Chile, Ediciones de las mujeres, 15, pp. 63-78.

Bruckner, P. y A. Finkielkraut (1979): El nuevo desorden amoroso, Barcelona, Anagrama.

Carracedo, R. (2006): "Por un análisis feminista de la prostitución", Mujeres en la periferia. Algunos debates sobre género y exclusión social, Calvo, Adelina et al. (Eds.), Barcelona, Icaria.

Castells, M. (1998): La era de la información. Economía, sociedad y cultura. Vol. 3: Fin de milenio, Madrid, Alianza editorial.

Cobo, R. (2015): "El cuerpo de las mujeres y la sobrecarga de sexualidad", Investigaciones feministas, vol. 6. Universidad Complutense de Madrid, pp. 7-19.

Cobo, R. (1995): Fundamentos del patriarcado moderno. Jean Jacques Rousseau, Madrid, Cátedra, col. Feminismos.

De León, M. E. (2012): Las ocultas. Una experiencia de la prostitución, Madrid, Turner.

Díez, E. (2012): "El papel de los hombres en la prostitución", Nuestra Bandera. Revista de debate político y teórico, II (232), pp. 39-54.

Fernández Oliver, B (200.): "La prostitución a debate en España", Documentación Social, 144, pp. 75-89.

Fondation Scelles. Under the Direction of Ives Chapernel. Deputy General Prosecutor of the Supreme Court of France. President of the Fondation Scelles (2012): Sexual Explotation. Prostitucion and Organized Crime, Paris, Economica. (Traducción del francés para varios países).

Fraser, N. (2012): "Reflexiones en torno a Polanyi y la actual crisis capitalista", en Papeles de relaciones ecosociales y cambio global, $\mathrm{n}^{\circ} 118$, pp. 13-28.

Fraser, N. (1991): "Usos y abusos de las teorías francesas del discurso para la política feminista", en Hiparquía. Publicación de la Asociación Argentina de Mujeres en Filosofía, vol. IV, $\mathrm{n}^{\circ} 1$.

Gimeno, B. (2012): La prostitución, Barcelona, Bellaterra.

Hofman, C. (1997): “¿Es la prostitución un derecho humano?”, www.notivida.com.ar

Jeffreys, S. (2002): Conferencia impartida en el Seminario sobre los Efectos de la Legalización de las actividades de la prostitución, www.pce.es/secretarias/sec.mujer

Jeffreys, S. (2012): La industria de la vagina. Laeconomía política de la comercialización global del sexo, Buenos Aires, Paidós.

Informe criminológico. Trata de seres humanos con fines de explotación sexual (2005): Unidad Técnica. Policía Judicial, Guardia Civil, Madrid.

Informe de la ponencia sobre la prostitución en nuestro país (2007): Cortes Generales. Comisión Mixta de los Derechos de la Mujer y de la Igualdad de Oportunidades. Aprobada en sesión de la ponencia de 13 de marzo de 2007. 
Juliano, D. (2002): La prostitución. El espejo oscuro, Barcelona, Icaria.

Maqueda, M. L. (2009): Prostitución, feminismos y derecho penal, Granada, Comares Paris, C. (2012): "La degradación del ser humano en la prostitución", Nuestra Bandera. Revista de debate político y teórico, vol. II, $\mathrm{n}^{\circ} 232$, pp. 57-76.

Osborne, R. (ed.) (2004): Trabajador@as del sexo. Derecho, migraciones y tráfico en el siglo XXI, Barcelona, Bellaterra.

Pateman, C. (1995): El contrato sexual, Madrid, Anthropos.

Posada, L. (2015): Filosofía, crítica y (re)flexiones feministas, Madrid, Fundamentos.

Poulin, R. (Coord.) (2005): Prostitution. La mondialisation incarnée, Paris, Sylepse.

Poulin, R. (2009): Entrevista, https://elbosquedelascenizas.wordpress.com

Sassen, S. (2003): Contrageografias de la globalización. Género y ciudadanía en los circuitos transfronterizos, Madrid, Traficantes de Sueños.

Sassen, S. (2013): “Actores y espacios laborales de la globalización”, en C. Díaz y S. Dema (eds.), Sociología y Género, Madrid, Tecnos.

Szil, P. (2007): "Los hombres, la pornografía y la prostitución", ponencia presentada al Congreso de los Diputados de España, en BOE, 379, pp. 84-89.

Vigil, C. y M. Vicente (2006): "Prostitución, liberalismo sexual y patriarcado", en www.malostratos.org.

Walter, N. (2010): Muñecas vivientes. El regreso del sexismo, Madrid, Turner. 